\title{
The time lag between introduction and escape from cultivation of alien woody plant species decreases with polyploidization
}

\author{
M. Brändle and R. Brandl \\ Animal Ecology, Department of Ecology, Faculty of Biology, Philipps-Universität Marburg, \\ Karl-von-Frisch Str. 8, 35032 Marburg, Germany \\ Correspondence to: R. Brandl (brandlr@staff.uni-marburg.de)
}

Received: 21 November 2011 - Revised: 22 March 2012 - Accepted: 2 April 2012 - Published: 20 April 2012

\begin{abstract}
The time between introduction of an alien species and escape from cultivation shows considerable variation among species. One hypothesis to explain this variation of the time lag invokes the evolution of genotypes adapted to the conditions of the new environment. Here, we analyse the variation in time lags among 53 alien woody plant species in Germany. Accounting for the effects of time since introduction, growth form (trees versus shrubs), biogeography and taxonomic isolation (presence or absence of a native congener in the adventive area) we found that the time lag decreases with increasing polyploidization. By contrast, the haploid chromosome number was not significantly related to the time lag. These results provide evidence for the hypothesis that recent genome duplication events are important for a fast escape from cultivation of an alien woody plant species. We suggest that a large number of duplicated chromosomes increase the partitioning of the genome and hence the average rate of recombination between loci facilitating the formation of adaptive genotypes.
\end{abstract}

\section{Introduction}

Alien species are among the major factors that lead to a worldwide decrease of biodiversity (Vitousek et al., 1997). The invasion trajectory of a plant species into a new range may be subdivided into several successive phases (Sakai et al., 2001): (i) introduction of an alien plant into the new area, (ii) the casual stage, during which alien species survive and irregularly reproduce, (iii) the naturalization phase in which alien species regularly reproduce and (iv) the invasive (exponential) phase, where alien species spread across the landscape and enter natural habitats. The early phases during invasion are not well understood (Hobbs and Humphries, 1995; Pyšek and Hulme, 2005). The lag phase may be defined as the time span between introduction and some of the subsequent phases. The exact definition of the lag phase, however, differs among authors. While most researchers refer to the lag phase as the time between the beginning of the casual phase and the start of the exponential phase (e.g. Williamson et al., 2005; Dietz and Edwards, 2006) others define the time lag as the time between introduction and first records in the wild (Kowarik, 1992, 1995).

Several authors suggested that the evolution of novel genotypes either by hybridization with native species and/or populations during the early phases of invasion may be important for the success of alien species (Ellstrand and Schierenbeck, 2000). The empirical support for the hybridization hypothesis, however, is not convincing (Sakai et al., 2001; Lavergne and Molofsky, 2007). Nevertheless, the idea that reorganizations of the genome are an essential factor during invasions predicts also that the length of the time lag should vary among introduced species (e.g. Kowarik, 1992; Williamson et al., 2005). Species with long generation times should thereby need more time to evolve suitable genotypes than species with short generation times (Kowarik, 1995, "genotypic hypothesis"; Hobbs and Humphries, 1995, see also Kubešová et al., 2010). In contrast several ecological hypotheses may also explain variations in the length of 
the lag. The "demographic hypothesis" assumes that the probability of long distance-dispersal increases the potential to colonize suitable habitats facilitating population growth (Cousens and Mortimer, 1995). The "extrinsic hypothesis" suggests that episodic environmental events or changing environmental conditions trigger the invasion process and therefore also determine the time lag (Hobbs and Humphries, 1995; Sakai et al., 2001). A number of studies showed that there is considerable variation in the time lag among species (e.g. Kowarik, 1992; Williamson et al., 2005). For example Acer negundo needed more than $150 \mathrm{yr}$ to escape from cultivation, whereas Prunus serotina escaped in less than $30 \mathrm{yr}$ (Kowarik, 1992). However, empirical support for the three hypotheses is limited and even contradictory. Therefore, Pyšek and Hulme (2005) suggested that the variation of time lags among species may be even a statistical artefact.

Chromosome numbers vary considerably among plant species (Bennett et al., 2000; Soltis and Soltis, 2000; Soltis et al., 2003a). While large haploid numbers of chromosomes are explained with repeated ancient rounds of polyploidization ("palaeoploids", e.g. Grant, 1963; Goldblatt, 1980) with subsequent diploidization., "apparent" polyploids point to evolutionary recent polyploidization events. Polyploids often exhibit broader ecological tolerances than their diploid ancestors (Otto and Whitton, 2000; te Beest et al., 2012) and therefore may be able to cope with unfavourable environmental conditions (Hijmans et al., 2007). This advantage associated with polyploidization has been explained by the larger number of non-linked gene duplicates which increase genetic variance and therefore the speed of adaptive evolution (Lee, 2002; Soltis et al., 2003a, b). Furthermore there is some evidence that polyploidy leads to changes in morphology and physiology of species and facilitate invasiveness (see te Beest et al., 2012). For instance polyploids invest more in the production of shoots and rhizomes increasing competitiveness (Schlaepfer et al., 2010). Thus, it is not surprising that the world's worst weeds are polyploids (Brown and Marshall, 1981) and that polyploids occur in higher frequencies among alien plants (Pandit et al., 2006, 2011; te Beest et al., 2012).

Here we test the idea that the time lag of an alien species should decrease either with an increasing number of chromosomes or increasing level of polyploidization. Thereby we consider the haploid chromosome number and the level of polyploidization (e.g. diploid, tetraploid, hexaploid). Hence, we are able to distinguish between the effects of ancient and recent polyploidizations.

\section{Material and methods}

We considered 53 alien woody plant species (28 trees and 25 shrubs) occurring in Germany and in particular, in Brandenburg (Kowarik, 1992). These species have been brought to Brandenburg deliberately as agricultural and/or horticultural plants. The time lag was estimated as the time (in years) between the first cultivation in Brandenburg and the first record in the wild in Brandenburg (including Berlin). Species which are native in Central Europe but are known to have been introduced to Brandenburg were excluded. For three species, the data for the first cultivation in Brandenburg were not available. For these species the time lag was calculated as the time span between the first cultivation in Europe and the first record in the wild in Brandenburg. It is important to note that the time lags analysed in our study are defined as the time span between first record of cultivation and the first record in the wild (Kowarik, 1992, 1995). Other authors (e.g. Sakai et al., 2001; Dietz and Edwards, 2006, see introduction) define the time lag as the time span between escape from cultivation and the beginning of the exponential phase. The beginning of spread, however, seems to depend on the geographical scale (e.g. local habitat patch versus region or landscape) on which invasion processes are analysed (Pyšek and Hulme, 2005).

Data on the haploid chromosome number and the level of polyploidization were extracted from the online databases BIOLFLOR (Klotz et al., 2002) and Plant DNA Cvalues (Bennett and Leitch, 2005). To account for confounding effects we included the time span since introduction (Kowarik, 1992), growth form (tree versus shrub), biogeography and occurrence of phylogenetically related natives (extracted from Schmeil et al., 2000) into a general linear model. The time span since introduction was considered to account for an obvious constraint: plants introduced very recently can only show short time lags and therefore one expects a decrease in the time lag with decreasing time since introduction. Two measures of time since introduction were used: first, the time period (in years) from the first documented occurrence of an alien plant species in Brandenburg or Berlin to 2008 (Kowarik, 1992), and second, the time (in years) that the considered alien species had been cultivated in Europe (Kowarik, 1992). Many alien species in Europe were at first cultivated in Southern Europe and later brought to Central and Northern Europe. Hence, our second measure accounts also for time a species may have evolved adaptation to the general European environment. However, since both measures showed a strong positive correlation $(r=0.82)$ we calculated a PCA and used the species scores of the first PCAaxis in subsequent analyses. This axis accounted for $95 \%$ of the variation.

We considered the growth form as a surrogate for generation time which can be used for a first test of the "genotypic hypothesis" (see introduction). Shrubs or climbers are smaller and typically characterized by a shorter generation time than long-lived trees. Shrub or climber species were coded as zero and trees as one respectively. Data on the species biogeography were taken from Brändle et al. (2008). We scored the species according to the distance of their native range to Central Europe (for details see Brändle et al., 2008). We considered biogeography since one may argue that an alien plant from a distant biogeographic realm has 
evolved in an ecosystem with little resemblance to Europe. Hence pre-adaptations may be few compared to alien species from adjacent regions. Occurrence of phylogenetically related natives was included for three reasons. First, a number of studies showed that species with no close relatives in the area of introduction are on average more successful than those with congeners in the area (Keane and Crawley, 2002). Second, contrary to the former it has been argued that especially at larger scales, alien plants with closely related native species are more likely to become successful as pre-adaptations to certain environmental conditions facilitate co-existence with natives (Diez et al., 2008). Third, close relatives allow for hybridization which may accelerate escape from cultivation (see introduction). Taxonomic proximity (occurrence of at least one native congener) was coded as one (present) and zero (absent).

We used a simple general linear model (type I sum of squares) to analyse our data. Prior to all analyses, the time lag and the number of chromosomes were $\log _{10^{-}}$ transformed. Comparative studies can suffer from "pseudoreplication" when species are treated as independent data (Harvey, 1996). We used nested analysis of variance to calculate the amount of variance accounted for by various taxonomic levels (genus, family, order). If most of the variation in time lag is among species within genera, a phylogenetic corrected analysis is not necessary (Freckleton et al., 2002). We used " $R$ " (R Development Core Team, 2004) and the function "varcomp" within the package APE to calculate variance components (Paradis et al., 2004). These analyses revealed that, by far, most of the variation in time lags $\left(\log _{10^{-}}\right.$ transformed) was among species within genera (85\%). $11 \%$ were distributed among orders and $4 \%$ among genera within families. For the family level we found only minor variance components $(<1 \%)$. All analyses were therefore carried out on the species level. Note also that in our data set only six genera $(13 \%)$ out of 48 were represented by more than one species.

\section{Results}

Time lags showed considerable variation among alien woody plant species (Table 1) and ranged from 29 (Prunus serotina) to $415 \mathrm{yr}$ (Prunus persica). Haploid chromosome number ranged between 7 (e.g. Rosa rugosa) and 24 chromosomes (Syringa vulgaris). Polyploidy varied between diploid (the bulk of species, see Table 1) and hexaploid (e.g. Ulex europaeus). Haploid number of chromosomes was not correlated with the level of polyploidization $(r=0.04, P=0.78)$. We found no significant relationship between the time lag and the haploid chromosome number $(r=-0.13, P=0.36$, Fig. 1, left). By contrast, there was a significant negative correlation between the time lag and polyploidization $(r=-0.39, P=0.03$, Fig. 1, right). General linear modelling revealed the expected strong positive relationship between
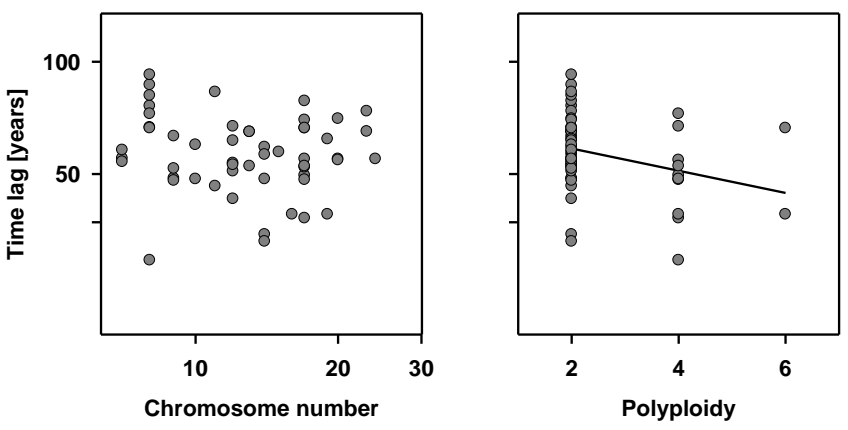

Figure 1. (left) Correlation between the time lag (in years) of alien plants in the state Brandenburg of Germany and their haploid number of chromosomes $(n=53, r=-0.13, P=0.36$ ). (right) Correlation between the time lag of alien plants and polyploidy $(n=53$, $r=-0.39, P=0.03)$. See text for further explanations. Note that in the left panel both axes were $\log _{10}$-transformed.

time since introduction and the time lag (Table 2). Nevertheless even after accounting for all other independent variables and even after adding the haploid chromosome number into the model, we found a significant negative relationship between the time lag and polyploidization (Table 2). This result hold also after recoding the level of polyploidization from a continuous variable to factor with two levels (Table 2). Note also, that neither taxonomic proximity nor growth form or biogeography was significantly related to the time lag.

\section{Discussion}

Our data show a decrease of the time lag with increasing polyploidization. By contrast, the time lag was not significantly related to the number of chromosomes suggesting that rather recent gene duplications than ancient ones increase the likelihood for a fast escape from cultivation. Except for the control variable "time since introduction" all other considered variables were not related to our measure of the time lag.

Several authors noted that species with many chromosomes have a polyploid origin (Soltis and Soltis, 2000; Soltis et al., 2003b; Paun et al., 2007). There is ample evidence that during the evolutionary history of species, repeated rounds of polyploidization events have contributed to the present structure of the genomes, in particular in families of woody angiosperms which provide the bulk of the species analysed in this study (Soltis et al., 2003b, see Table 1). However our analysis indicates that not ancient polyploidization but rather recent polyploidization events are important for the escape from cultivation. We are currently not able to present a detailed understanding for these differences. Little is known about the temporal dynamics of the genetic variance in polyploids (Doyle et al., 2008). But one may speculate that the evolutionary potential of old polyploidizations declines over time. Thereby genome downsizing (e.g. Leitch and 
Table 1. Table of the alien woody plant species analysed in the present study. The lag phase (years between introduction and escape from cultivation), time since introduction (years), growth form $(0=$ shrub or climber, $1=$ tree $)$, taxonomic proximity $(0=$ without native congener, $1=$ with native congener) the haploid chromosome number and the level of polyploidy of the species are listed.

\begin{tabular}{|c|c|c|c|c|c|c|c|}
\hline Alien woody plant species & $\begin{array}{r}\text { Time } \\
\text { lag }\end{array}$ & $\begin{array}{r}\text { Time since } \\
\text { introduction to } \\
\text { Europe }\end{array}$ & $\begin{array}{r}\text { Time since } \\
\text { introduction to } \\
\text { Brandenburg or } \\
\text { Berlin }\end{array}$ & $\begin{array}{l}\text { Growth } \\
\text { form }\end{array}$ & $\begin{array}{l}\text { Taxonomic } \\
\text { proximity }\end{array}$ & $\begin{array}{r}\text { Haploid } \\
\text { Chromosome } \\
\text { number }\end{array}$ & Polyploidy \\
\hline Acer negundo & 183 & 320 & 272 & 1 & 1 & 13 & 2 \\
\hline Aesculus hippocastanum & 124 & 432 & 345 & 1 & 0 & 20 & 2 \\
\hline Ailanthus altissima & 122 & 263 & 228 & 1 & 0 & 20 & 4 \\
\hline Amelanchier alnifolia & 53 & 120 & 88 & 0 & 1 & 17 & 4 \\
\hline Amelanchier lamarckii & 98 & 385 & 223 & 0 & 1 & 17 & 4 \\
\hline Amelanchier spicata & 92 & 208 & 208 & 0 & 1 & 17 & 4 \\
\hline Amorpha fruticosa & 93 & 284 & 223 & 0 & 0 & 10 & 4 \\
\hline Berberis thunbergii & 93 & 158 & 121 & 0 & 1 & 14 & 2 \\
\hline Buddleja davidii & 56 & 121 & 112 & 0 & 0 & 19 & 4 \\
\hline Caragana arborescens & 195 & 256 & 239 & 0 & 0 & 8 & 2 \\
\hline Chaenomeles speciosa & 110 & 174 & 144 & 0 & 0 & 17 & 2 \\
\hline Colutea arborescens & 265 & 448 & 414 & 0 & 0 & 8 & 2 \\
\hline Cornus alba & 84 & 267 & 235 & 1 & 1 & 11 & 2 \\
\hline Cydonia oblonga & 285 & 2008 & 414 & 1 & 0 & 17 & 2 \\
\hline Elaeagnus angustifolia & 147 & 325 & 272 & 1 & 0 & 14 & 2 \\
\hline Elaeagnus commutata & 42 & 195 & 186 & 0 & 0 & 14 & 2 \\
\hline Forsythia suspensa & 132 & 175 & 175 & 0 & 0 & 14 & 2 \\
\hline Fraxinus ornus & 246 & 448 & 272 & 1 & 1 & 23 & 2 \\
\hline Fraxinus pennsylvanica & 184 & 212 & 212 & 1 & 1 & 23 & 2 \\
\hline Kerria japonica & 172 & 204 & 195 & 0 & 0 & 9 & 2 \\
\hline Laburnum anagyroides & 198 & 448 & 345 & 1 & 0 & 12 & 4 \\
\hline Lonicera tatarica & 94 & 256 & 238 & 0 & 1 & 9 & 2 \\
\hline Lycium barbarum & 70 & 312 & 239 & 0 & 0 & 12 & 2 \\
\hline Mahonia aquifolium & 38 & 186 & 186 & 0 & 0 & 14 & 2 \\
\hline Malus domestica & 124 & 2008 & 345 & 1 & 1 & 17 & 2 \\
\hline Mespilus germanica & 193 & 2008 & 414 & 1 & 0 & 17 & 2 \\
\hline Parthenocissus inserta & 221 & 403 & 345 & 0 & 0 & 20 & 2 \\
\hline Philadelphus coronarius & 183 & 446 & 352 & 0 & 0 & 13 & 2 \\
\hline Physocarpus opulifolius & 91 & 325 & 239 & 0 & 0 & 9 & 2 \\
\hline Picea pungens & 104 & 145 & 127 & 1 & 1 & 12 & 2 \\
\hline Pinus strobus & 117 & 303 & 238 & 1 & 1 & 12 & 2 \\
\hline Populus $x$ canadensis & 165 & 258 & 221 & 1 & 1 & 19 & 2 \\
\hline Potentilla fruticosa & 125 & 308 & 272 & 0 & 1 & 7 & 2 \\
\hline Prunus armeniaca & 308 & 2008 & 351 & 1 & 1 & 8 & 2 \\
\hline Prunus cerasifera & 359 & 508 & 458 & 1 & 1 & 8 & 2 \\
\hline Prunus cerasus & 237 & 1508 & 458 & 1 & 1 & 8 & 4 \\
\hline Prunus domestica & 193 & 2008 & 414 & 1 & 1 & 8 & 6 \\
\hline Prunus persica & 415 & 2008 & 458 & 1 & 1 & 8 & 2 \\
\hline Prunus serotina & 29 & 385 & 212 & 1 & 1 & 8 & 4 \\
\hline Pseudotsuga menziesii & 112 & 181 & 156 & 1 & 0 & 13 & 2 \\
\hline Pyracantha coccinea & 217 & 379 & 402 & 0 & 0 & 17 & 2 \\
\hline Pyrus communis & 193 & 2008 & 414 & 1 & 1 & 17 & 2 \\
\hline Quercus cerris & 161 & 269 & 212 & 1 & 1 & 12 & 2 \\
\hline Quercus rubra & 114 & 284 & 235 & 1 & 1 & 12 & 2 \\
\hline Rhus hirta & 137 & 386 & 262 & 0 & 0 & 15 & 2 \\
\hline Robinia pseudoacacia & 152 & 385 & 336 & 1 & 0 & 10 & 2 \\
\hline Rosa multiflora & 141 & 204 & 167 & 0 & 1 & 7 & 2 \\
\hline Rosa rugosa & 119 & 163 & 167 & 0 & 1 & 7 & 2 \\
\hline Sorbaria sorbifolia & 108 & 249 & 212 & 0 & 0 & 9 & 2 \\
\hline Sorbus intermedia & 112 & 219 & 212 & 1 & 1 & 17 & 4 \\
\hline Syringa vulgaris & 124 & 446 & 345 & 1 & 0 & 24 & 2 \\
\hline Thuja occidentalis & 324 & 472 & 368 & 1 & 0 & 11 & 2 \\
\hline Ulex europaeus & 56 & 447 & 223 & 0 & 0 & 16 & 6 \\
\hline
\end{tabular}


Table 2. Effects of time since introduction, taxonomic proximity, growth form, biogeography, chromosome number and polyploidy on the time lag. The table shows the results of a linear model. The time lag and the chromosome number were $\log _{10}$-transformed before analyses. Significant F-values $(P \leq 0.05)$ are printed in bold $(n=52)$. Recoding the level of polyploidization to a factors with two levels (yes/no) leads to almost the same results (for the factor polyploidization $F=6.6 ; P=0.014$ ).

\begin{tabular}{llll}
\hline Independent variables & \multicolumn{3}{c}{$\log _{10}$ Time lag } \\
\cline { 2 - 4 } & $\mathrm{d} f$ & $F$ & $P$ \\
\hline Time since introduction (PC1) & 1 & $\mathbf{3 9}$ & $<0.001$ \\
Taxonomic proximity & 1 & 0.001 & 0.97 \\
Growth form & 1 & 0.60 & 0.44 \\
Biogeography & 1 & 0.014 & 0.91 \\
Log $_{10}$ Chromosome number & 1 & 0.91 & 0.35 \\
Level of polyploidy $_{\text {Residuals (MSS) }}$ & 1 & $\mathbf{7 . 5}$ & 0.0086 \\
\hline
\end{tabular}

Benett, 2004) is an important process. But downsizing may enhance stability of the polyploid genome and reduces biochemical costs (Leitch and Benett, 2004, see below). Therefore a trade-off between the evolutionary potential and stability of polyploidy may exist.

Polyploids are on average more successful invaders (e.g. Stebbins, 1971; Lee, 2002; Pandit et al., 2006, 2011; Hijmans et al., 2007; Stenberg et al., 2003; Schlaepfer et al., 2008). A number of mutually non-exclusive mechanisms have been proposed to explain this observation (Soltis and Soltis, 2000): (i) polyploid species generally maintain higher levels of heterozygosity than their diploid relatives providing the evolutionary potential to evolve adaptive and competitive genotypes. (ii) Polyploid species are less prone for inbreeding depression and can tolerate higher levels of selfing than diploids. Selfing is important during the early stages of invasion when populations are small and scattered. (iii) Extensive genomic rearrangements such as intergenomic translocations are common in polyploids producing novel genotypes within few generations. (iv) Finally, polyploidy increases the average rate of recombination's between loci and therefore decreases linkage between genes (Otto and Whitton, 2000). All these processes may also explain our observation that the time-lag decreases with polyploidization.

On longer time scales, polyploidization is often followed by diploidisation (e.g. Doyle et al., 2008). Diploidisation is accompanied by several important changes in genomic constitution (Soltis et al., 2003b) which may also increase adaptability (e.g. Leitch and Bennett, 2004; Bossdorf et al., 2008; Soltis et al., 2003b; Leitch and Leitch, 2008). All the proposed mechanisms suggest that adaptations evolve more rapidly in polyploids than in their diploid relatives. However, there is only limited empirical support for the hypothesis that the evolutionary rates differ between polyploids and diploids (Soltis et al., 2003b). While some studies reported an in- crease in the ratio of non-synonymous to synonymous nucleotide substitutions or higher nucleotide diversity in polyploids (Sun et al., 2007), others found the opposite pattern (Caldwell et al., 2004) or no difference (Cedroni et al., 2003). This suggests that the success of polyploids is not the result of the accumulation of mutations in non-functional genes that become functional within a new environment. Rearrangement of existing genetic information into adaptive genotypes seems to be far more important.

Higher levels of polyploidy with the associated evolutionary potential might explain a fast escape from cultivation but not necessarily also the success of an alien species. We found no relationship between time lag and distributional range of the analysed alien woody plants in Germany (across species, $n=47, r=-0.17, P=0.25$, distributional range was measured from grids of $10 \mathrm{~min}$ longitude $\times 6$ min latitude, for details see Brändle et al., 2008; see also Kowarik, 1995). It is important to bear in mind that the invasion of a species is a complex multistage process depending on intrinsic as well as on extrinsic factors (Dietz and Edwards, 2006). Intrinsic factors comprise species traits such as genetic constitution, generation time, dispersal ability, seed size and longevity, native range and propagule pressure (Hamilton et al., 2005; Pyšek and Richardson, 2007). Extrinsic factors include habitat characteristics (e.g. habitat availability), disturbance, occupation of vacant niches and competitive interactions with native or other alien species (Sakai et al., 2001). The importance of these factors seems to be contextdependent and may vary during the different stages of the invasion (e.g. Pyšek and Richardson, 2007). Finally, interactions with other trophic levels such as herbivores or microbes are also important for the success of an invader (Callaway and Maron, 2006).

Besides the decrease of the time lag with polyploidization our analyses revealed that short time-lags are more commonly found within alien plants introduced very recently. Of course this result is expected because plants introduced a longer time ago can show both short and small time lags while plants introduced very recently can if at all exhibit only short time lags. Nevertheless, there are other processes that may contribute to this trend. For example, the relationship may depend on higher recorder activity and awareness of the public in recent times which facilitated the detection of escaped populations (Williamsen et al., 2005). Furthermore, the recent changes in the landscape due to increasing human populations and activity may facilitate the escape from cultivation (Williamsen et al., 2005).

Although the results of our study are in line with certain mechanistic explanations about the importance of polyploidzation for a fast escape from cultivation we want to point to several shortcomings of our approach. First, our data are restricted to woody plants that have been brought deliberately to Brandenburg. Hence, our data set is biased. In particular without herbaceous species our test of the "generation time"-hypothesis is very weak. Note also that our surrogate 
for the generation time was very crude. Second, our measure of the time lag comprises "only" the time between introduction and escape from cultivation. Such a definition of the time lag is rather unusual (see introduction). Therefore, our study does not allow drawing conclusions about the triggers of the naturalization and the invasive phase. Third, there is no direct evidence for the species included in our analysis that greater haploid number of chromosomes are due to ancient polyploidization with subsequent diploidization. Fourth, we did not touch the issue whether the type of polyploidization e.g. allopolyploidy versus autopolyploidy affect the outcomes of our analysis. Such data are currently not available, but need to be considered in future analyses, because there is some evidence that allopolyploidy is the more efficient mechanism to accumulate evolutionary novelties (Doyle et al., 2008).

Overall, we showed that time lags of alien woody plant species decreased with increasing level of polyploidy. However it is important to bear in mind that our data set covers only the time lag between introduction and escape form cultivation. We also acknowledge that we are still far from a mechanistic understanding of the variation in the time lag of alien plants.

Edited by: H. Freitas

Reviewed by: J. Loureiro and another anonymous referee

\section{References}

Bennett, M. D. and Leitch, I. J.: Plant DNA C-values Database release 4.0, October 2005, http://www.kew.org/cval/homepage. html, 2005.

Bennett, M. D., Bhandol, P., and Leitch, I. J.: Nuclear DNA amounts in angiosperms and their modern uses -807 new estimates, Ann. Bot., 86, 859-909, 2000.

Bossdorf, O., Richards, C. L., and Pigliucci, M.: Epigenetics for ecologists, Ecol. Lett., 11, 106-115, 2008.

Brown, A. H. D. and Marshall, D. R: Evolutionary changes accompanying colonization in plants, in: Evolution Today, Proceedings of the Second International Congress of Systematic and Evolutionary Biology, edited by: Scudder, G. G. and Reveal, J. L., Carnegie-Mellon University, Pittsburgh, PA, USA, Hunt Institute for Botanical Documentation, 351-363, 1981.

Brändle, M., Kühn, I., Klotz, S., Belle, C., and Brandl, R.: Species richness of herbivores on exotic host plants increases with time since introduction of the host, Divers. Distrib., 14, 905-912, 2008.

Caldwell, K. S., Dvorak, J., Lagudah, E. S., Akhunov, E., Luo, M. C., Wolters, P., and Powell, W.: Sequence polymorphism in polyploid wheat and their D-genome diploid ancestor, Genetics, 167, 941-947, 2004.

Callaway, R. M. and Maron, J. L.: What have exotic plant invasions taught us over the past 20 years?, Trends Ecol. Evol., 21, 369374, 2006.

Cedroni, M. L., Cronn, R. C., Adams, K. L., Wilkins, T. A., and Wendel, J. F.: Evolution and expression of MYB genes in diploid and polyploid cotton, Plant Mol. Biol., 51, 313-325, 2003.
Cousens, R. and Mortimer, M.: Dynamics of weed populations, Cambridge University Press, New York, 1995.

Dietz, H. and Edwards, P. J.: Recognition that causal processes change during plant invasion helps explain conflicts in evidence, Ecology, 87, 1359-1367, 2006.

Diez, J. M., Sullivan, J. J., Hulme, P. E., Edwards, G., and Duncan, R. P.: Darwin's naturalization conundrum: dissecting taxonomic patterns of species invasions, Ecol. Lett., 11, 674-681, 2008.

Doyle, J. J., Flagel, L. E., Paterson, A. H., Rapp, R. A., Soltis, D. E., Soltis, P. S., and Wendel, J. F.: Evolutionary genetics of genome merger and doubling in plants, Annu. Rev. Genet., 42, 443-461, 2008.

Ellstrand, N. C. and Schierenbeck, K. A.: Hybridization as a stimulus for the evolution of invasiveness in plants?, P. Natl. Acad. Sci. USA, 97, 7043-7050, 2000.

Freckleton, R. P., Harvey, P. H., and Pagel, M.: Phylogenetic analysis and comparative data: a test and review of evidence, Am. Nat., 160, 712-726, 2002.

Goldblatt, P.: Polyploidy in angiosperms: Monocotyledons, in: Polyploidy: Biological relevance, edited by: Lewis, W. H., Plenum Press, New York, 219-239, 1980.

Grant, V.: The origin of adaptations, Columbia University Press, New York, USA, 1963.

Hamilton, M. A., Murray, B. R., Cadotte, M. W., Hose, G. C., Baker, A. C., Harris, C. J., and Licari, D.: Life-history correlates of plant invasiveness at regional and continental scales, Ecol. Lett., 8, 1066-1074, 2005.

Harvey, P. H.: Phylogenies for ecologists, J. Anim. Ecol., 65, 255263, 1996.

Hijmans, R. J., Gavrilenko, T., Stephenson, S., Bamberg, J., Salas, A., and Spooner, D. M.: Geographic and environmental range expansion through polyploidy in wild potatoes Solanum section Petota, Glob. Ecol. Biogeogr., 16, 485-495, 2007.

Hobbs, R. J. and Humphries, S. E.: An Integrated Approach to the Ecology and Management of Plant Invasions, Conserv. Biol., 9, 761-770, 1995.

Keane, R. M. and Crawley, M. J.: Exotic plant invasions and the enemy release hypothesis, Trends Ecol. Evol., 17, 164-169, 2002.

Klotz, S., Kühn, I., Durka, W. (Eds.): BIOLFLOR - Eine Datenbank zu biologisch-ökologischen Merkmalen der Gefässpflanzen in Deutschland, Schriftenreihe für Vegetationskunde, Bundesamt für Naturschutz, Bonn, 2002.

Kowarik, I:. Einführung und Ausbreitung nichteinheimischer Gehölzarten in Berlin und Brandenburg und ihre Folgen für Flora und Vegetation. Ein Modell für die Freisetzung gentechnisch veränderter Organismen, Verhandlungen des Botanischen Vereins Berlin Brandenburg, Beiheft 3, 1992.

Kowarik, I.: Time lags in biological invasions with regard to the success and failure of alien species, in: Plant invasions - general aspects and special problems, edited by: Pyšek, P., Prach, K., Rejmánek, M., and Wade, M., SPB Academic Publishing, Amsterdam, 15-38, 1995.

Kubešová, M., Moravcová, L., Suda, J., Jarošik, V., and Pyšek, P.: Naturalized plants have smaller genomes than their non-invading relatives: a flow cytometric analysis of the Czech alien flora, Preslia, 82, 81-96, 2010.

Lavergne, S. and Molofsky, J.: Increased genetic variation and evolutionary potential drive the success of an invasive grass, P. Natl. Acad. Sci. USA, 104, 3883-3888, 2007. 
Lee, C. E.: Evolutionary genetics of invasive species, Trends Ecol. Evol., 17, 386-391, 2002.

Leitch, A. R. and Leitch, I. J.: Perspective - Genomic plasticity and the diversity of polyploid plants, Science, 320, 481-483, 2008.

Leitch, I. J. and Bennett, M. D.: Genome downsizing in polyploid plants, Biol. J. Linn. Soc., 82, 651-663, 2004.

Otto, S. P. and Whitton, J.: Polyploid incidence and evolution, Annu. Rev. Genet., 34, 401-437, 2000.

Pandit, M. K., Tan, H. T. W., and Bisht, M. S.: Polyploidy in invasive plant species of Singapore, Bot. J. Linn. Soc., 151, 395-403, 2006.

Pandit, M. K., Pocock, M. J. O., and Kunin, W. E.: Ploidy influences raity and invasiveness in plants, J. Ecol., 99, 1108-1115, 2011.

Paradis, E., Claude, J., and Strimmer, K.: APE: analyses of phylogenetics and evolution in " $\mathrm{R}$ " language, Bioinformatics, 20, 289-290, 2004.

Paun, O., Fay, M. F., Soltis, D. E., and Chase, M. W.: Genetic and epigenetic alterations after hybridization and genome doubling, Taxon, 56, 649-656, 2007.

Pyšek, P. and Hulme, P. E.: Spatio-temporal dynamics of plant invasions: Linking pattern to process, Ecoscience, 12, 302-315, 2005.

Pyšek, P. and Richardson, D. M.: Traits associated with invasiveness in alien plants: Where do we stand?, in: Biological Invasions, edited by: Nentwig, W., Springer, Berlin, 97-125, 2007.

R Development Core Team: R, A language and environment for statistical computing, R Foundation for Statistical Computing, Vienna, Austria, 2004.

Sakai, A. K., Allendorf, F. W., Holt, J. S., Lodge, D. M., Molofsky, J., With, K. A., Baughman, S., Cabin, R. J., Cohen, J. E., Ellstrand, N. C., McCauley, D. E., O’Neil, P., Parker, I. M., Thompson, J. N., and Weller, S. G.: The population biology of invasive species, Annu. Rev. Ecol. Syst., 32, 305-332, 2001.

Schlaepfer, D. R., Edwards, P. J., Widmer, A., and Billeter, R.: Phylogeography of native ploidy levels and invasive tetraploids of Solidago gigantea, Mol. Ecol., 17, 5245-5256, 2008.
Schlaepfer, D. R., Edwards, P., and Billeter, R.: Why only tetraploid Solidago gigantea became invasive: a common garden comparison of ploidy levels, Oecologia, 163, 661-673, 2010.

Schmeil, O., Fitschen, J., Senghas, K., and Seibold, S.: Flora von Deutschland und angrenzender Länder, Quelle \& Meyer, Heidelberg, 2000.

Soltis, P. S. and Soltis, D. E.: The role of genetic and genomic attributes in the success of polyploids, P. Natl. Acad. Sci. USA, 9, 7051-7057, 2000.

Soltis, D. E., Soltis, P. S., Bennett, M. D., and Leitch, I. J.: Evolution of genome size in the angiosperms, Am. J. Bot., 90, 15961603, 2003a.

Soltis, D. E., Soltis, P. S., and Tate, J. A.: Advances in the study of polyploidy since plant speciation, New Phytol., 161, 173-191, 2003b.

Stebbins, G. L.: Chromosomal evolution in higher plants, AddisonWesley, Reading, 1971.

Stenberg, P., Lundmark, M., Knutelski, S., and Saura, A.: Evolution of clonality and polyploidy in a weevil system, Mol. Biol. Evol., 20, 1626-1632, 2003.

Sun, G. L., Daley, T., and Ni, Y.: Molecular evolution and genome divergence at RPB2 gene of the $\mathrm{St}$ and $\mathrm{H}$ genome in Elymus species, Plant Mol. Biol., 64, 645-655, 2007.

te Beest, M., Le Roux, J. J., Richardson, D. M., Brysting, A. K., Suda, J., Kubešová, M., and Pyšek, P.: The more the better? The role of polyploidy in fasciliating plant invasions, Ann. Bot., 109, 19-45, 2012.

Vitousek, P. M., Mooney, H. A., Lubchenco, J., and Melillo, J. M.: Human domination of earth's ecosystems, Science, 227, 494499, 1997.

Williamson, M., Pyšek, P., Jarosik, V., and Prach, K.: On the rates and patterns of spread of alien plants in the Czech Republic, Britain, and Ireland, Ecoscience, 12, 424-433, 2005. 